\title{
Hybrid Palladium Nanoparticles for Direct Hydrogen Peroxide Synthesis: The Key Role of the Ligand
}

\author{
Giacomo M. Lari ${ }^{+}$Begoña Puértolas ${ }^{+}$Masoud Shahrokhi, Núria López, and Javier Pérez- \\ Ramírez*
}

\begin{abstract}
Ligand-modified palladium nanoparticles deposited on a carbon carrier efficiently catalyze the direct synthesis of $\mathrm{H}_{2} \mathrm{O}_{2}$ and the unique performance is due to their hybrid nanostructure. Catalytic testing demonstrated that the selectivity increases with the HHDMA ligand content from $10 \%$ for naked nanoparticles up to $80 \%$, rivalling that obtained with state-of-the-art bimetallic catalysts ( $\left.\mathrm{HHDMA}=\mathrm{C}_{20} \mathrm{H}_{46} \mathrm{NO}_{5} \mathrm{P}\right)$. Furthermore, it remains stable over five consecutive reaction runs owing to the high resistance towards leaching of the organic moiety, arising from its bond with the metal surface. As rationalized by density functional theory, this behavior is attributed to the adsorption mode of the reaction intermediates on the metal surface. Whereas they lie flat in the absence of the organic shell, their electrostatic interaction with the ligand result in a unique vertical configuration which prevents further dissociation and over-hydrogenation. These findings demonstrate the importance of understanding substrate-ligand interactions in capped nanoparticles to develop smart catalysts for the sustainable manufacture of hydrogen peroxide.
\end{abstract}

$H$ ydrogen peroxide, $\mathrm{H}_{2} \mathrm{O}_{2}$, attracts growing attention as a green alternative to traditional stoichiometric oxidants in a wide range of applications within the textile, pulp bleaching, waste water treatment, metallurgy, cosmetic, and pharmaceutical industries. Owing to the advantages of its use, that is, the high atom economy and the generation of water as the only byproduct, ${ }^{[1]}$ an increase of its global market value from 3.7 to 6.0 billion USD between 2014 and 2023 is forecasted. ${ }^{[2]}$ Nowadays, the production of $\mathrm{H}_{2} \mathrm{O}_{2}$ relies exclusively on the anthraquinone process, which, despite being safe and suitable for continuous operation, involves the use of quinones and solvents resulting in energy-intensive purification steps and the generation of high amounts of waste, thus being competitive only at large scale. ${ }^{[1,3]}$ The direct synthesis of $\mathrm{H}_{2} \mathrm{O}_{2}$ is an appealing alternative that has the potential to be exploited in decentralized plants at any scale due to the 1) absence of

[*] G. M. Lari, ${ }^{[+]}$Dr. B. Puértolas, ${ }^{[+]}$Prof. Dr. J. Pérez-Ramírez Institute for Chemical and Bioengineering

Department of Chemistry and Applied Biosciences, ETH Zurich

Vladimir-Prelog-Weg 1, 8093 Zurich (Switzerland)

E-mail: jpr@chem.ethz.ch

Dr. M. Shahrokhi, Prof. Dr. N. López

Institute of Chemical Research of Catalonia (ICIQ) and

Barcelona Institute of Science and Technology

Av. Països Catalans 16, 43007 Tarragona (Spain)

$\left.{ }^{+}\right]$These authors contributed equally to this work.

(2) Supporting information and the ORCID identification number(s) for the author(s) of this article can be found under http://dx.doi.org/10. 1002/anie.201610552. organic substrates, 2) use of green solvents such as water or methanol, and 3) simplified purification. ${ }^{[1,4]}$ Its applicability has been widely investigated as such or in tandem with selective oxidation reactions using heterogeneous or, seldom, homogeneous catalysts. ${ }^{[5]}$ Albeit the number of advantages over the traditional route, its industrial implementation has been hindered by the limited selectivity of the most active catalyst identified, that is, supported $\mathrm{Pd}$ nanoparticles (NPs). ${ }^{[6]}$ Indeed, besides facilitating the reaction between molecularly adsorbed $\mathrm{O}_{2}$ and $\mathrm{H}$ atoms, $\mathrm{Pd}$ NPs favor $\mathrm{O}_{2}$ dissociation leading to undesired water formation (Scheme 1). ${ }^{[7]}$ To overcome this limitation, the addition of a second metal, chiefly Au or Sn, which was shown to generate active sites that prevent $\mathrm{O}-\mathrm{O}$ bond cleavage, resulted in the most selective catalysts reported to date. ${ }^{[8]}$ Still, the added loading of costly and/or toxic metals hampers their widespread use.
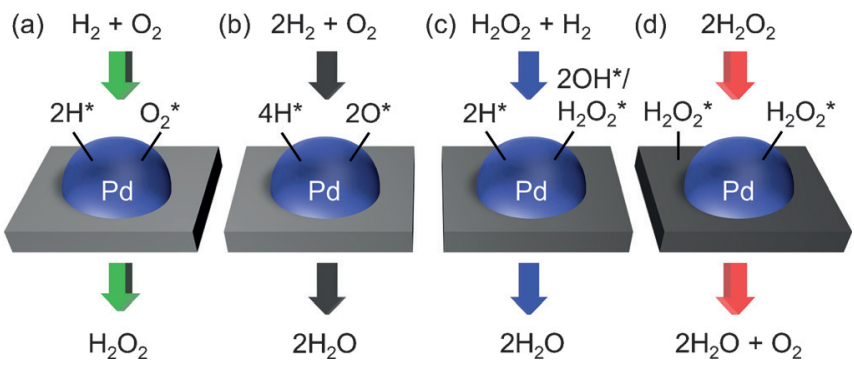

Scheme 1. Reactants, products, and relevant adsorbed intermediates in the a) direct synthesis of $\mathrm{H}_{2} \mathrm{O}_{2}$ and the side reactions leading to water formation by b) unselective $\mathrm{O}_{2}$ hydrogenation, c) $\mathrm{H}_{2} \mathrm{O}_{2}$ hydrogenation, and d) $\mathrm{H}_{2} \mathrm{O}_{2}$ decomposition over supported $\mathrm{Pd}$ catalysts.

In our quest to develop a superior catalyst, we were attracted by nanostructured hybrid materials, incorporating active metal NPs covered by an adsorbed layer of large organic molecules, such as polymers or surfactants. ${ }^{[9]}$ The latter not only prevent the aggregation of the active phase, but were also demonstrated to boost the selectivity in the stereospecific hydrogenation of carbonyl groups, the partial hydrogenation of alkynes, nitroaromatics, and unsaturated epoxides, and the alcoholysis of silanes owing to the blockage of unselective facets, the modification of the adsorption energies of reactants, intermediates, and products, the precise control of surface structures, or the interfacial electronic effect. ${ }^{[10]}$ Despite these encouraging results, they remain overlooked for direct $\mathrm{H}_{2} \mathrm{O}_{2}$ synthesis, where only poly(vinyl alcohol) (PVA)-capped Pd particles were recently suggested 
to limit $\mathrm{O}_{2}$ dissociation. ${ }^{[11]}$ Although the initial $\mathrm{H}_{2} \mathrm{O}_{2}$ selectivity was remarkable (ca. $95 \%$ ), it rapidly decreased due to leaching of the organic moiety, resulting in particle agglomeration. Herein, we show for the first time the suitability of carbon-supported, hexadecyl-2-hydroxyethyl-dimethyl ammonium dihydrogen phosphate $\left(\mathrm{C}_{20} \mathrm{H}_{46} \mathrm{NO}_{5} \mathrm{P}\right.$, HHDMA)capped Pd NPs as catalyst in the direct synthesis of $\mathrm{H}_{2} \mathrm{O}_{2}$. This commercially available material benefits from the nontoxic nature of the ligand and its hybrid structure has been proved stable in alkyne hydrogenation. ${ }^{[10 \mathrm{~b}]}$ Furthermore, we demonstrate through the combination of experimental and computational evidences based on density functional theory (DFT) the crucial role of the ligand in attaining an efficient catalyst. To this end, a series of Pd catalysts with $0.5-0.8 \mathrm{wt} \%$ metal loading labelled as $\mathrm{Pd}-\mathrm{HHDMA}_{n} / \mathrm{C}$, where $n=1-5$ denotes increasing HHDMA/Pd molar ratios, ${ }^{[12]}$ and a catalyst (1.0 wt \% Pd loading) featuring naked NPs prepared by dry impregnation $(\mathrm{Pd} / \mathrm{C})$ were evaluated. Additionally, a titanium silicate-supported Pd material (Pd-HHDMA 5 /TiS) was confronted to its $\mathrm{C}$-supported counterpart to unravel the role of the support. Compositional analysis of the solids (Table 1)

Table 1: Characterization data of the Pd catalysts.

\begin{tabular}{|c|c|c|c|c|}
\hline Catalyst & $\begin{array}{l}\mathrm{Pd}^{[\mathrm{a}]} \\
{[\mathrm{wt} \%]}\end{array}$ & $\begin{array}{l}\mathrm{HHDMA} / \mathrm{Pd}^{[a]} \\
{\left[\mathrm{mol} \mathrm{mol}^{-1}\right]}\end{array}$ & $\begin{array}{l}\mathrm{N}^{[\mathrm{b}]} \\
{[\mathrm{wt} \%]}\end{array}$ & $\begin{array}{l}D_{\mathrm{CO}}{ }^{[c]} \\
{[\%]}\end{array}$ \\
\hline $\mathrm{Pd} / \mathrm{C}$ & 1.0 & 0.0 & 0.0 & 5 \\
\hline $\mathrm{Pd}-\mathrm{HHDMA} / \mathrm{C}$ & 0.7 & 0.7 & 0.1 & 12 \\
\hline $\mathrm{Pd}-\mathrm{HHDMA}_{2} / \mathrm{C}$ & 0.8 & 1.0 & 0.2 & 13 \\
\hline $\mathrm{Pd}-\mathrm{HHDMA}_{3} / \mathrm{C}$ & 0.6 & 4.3 & 0.3 & 12 \\
\hline $\mathrm{Pd}-\mathrm{HHDMA}_{4} / \mathrm{C}$ & 0.5 & 8.2 & 0.4 & 13 \\
\hline $\mathrm{Pd}-\mathrm{HHDMA}_{5} / \mathrm{C}$ & 0.6 & 11.1 & 0.7 & 10 \\
\hline $\mathrm{Pd}-\mathrm{HHDMA} / \mathrm{TiS}$ & 0.5 & 8.3 & 0.5 & 14 \\
\hline
\end{tabular}

[a] Inductively coupled plasma-optical emission spectroscopy (ICPOES). [b] Elemental analysis. [c] Pd dispersion by CO pulse chemisorption.

revealed that both the $\mathrm{N}$ content and HHDMA/Pd molar ratio increased from $\mathrm{Pd}-\mathrm{HHDMA}_{1} / \mathrm{C}$ to $\mathrm{Pd}-\mathrm{HHDMA}_{5} / \mathrm{C}$ in line with the higher amount of ligand used in the preparation. Transmission electron microscopy (TEM) (Figure 1) showed that the Pd NPs possessed a uneven spherical shape with an average diameter of around $4 \mathrm{~nm}$. Despite they were unevenly distributed over the carbon support, no evidence of particle agglomeration was observed, which is related to the function of the ligand moiety in separating the metal phase during the synthesis. Indeed, examination of the Pd dispersion (Table 1) revealed similar values for all the HHDMA-modified samples, ${ }^{[13]}$ which was higher than that attained via conventional impregnation $(\mathrm{Pd} / \mathrm{C})$.

Assessment of the catalytic response of the $\mathrm{Pd} / \mathrm{C}$ catalyst in the direct synthesis of $\mathrm{H}_{2} \mathrm{O}_{2}$ displayed comparable results to those previously reported for these materials. ${ }^{[6]}$ Upon an increase of the HHDMA ligand content (Figure 2a), augmented $\mathrm{H}_{2} \mathrm{O}_{2}$ productivity as well as selectivity to $\mathrm{H}_{2} \mathrm{O}_{2}$ was observed. In line with its highest ligand content, $\mathrm{Pd}-$ $\mathrm{HHDMA}_{5} / \mathrm{C}$ exhibited the highest productivity $\left(8.4 \mathrm{~mol}_{\mathrm{H}_{2} \mathrm{O}_{2}} \mathrm{~h}^{-1} \mathrm{~g}_{\mathrm{Pd}}{ }^{-1}\right)$ and selectivity $(80 \%)$, surpassing most of the state-of-the-art materials (Table 2). The $\mathrm{H}_{2} \mathrm{O}_{2}$ selectiv-

Table 2: Comparison of the performance of $\mathrm{Pd}-\mathrm{HHDMA} / \mathrm{C}$ with state-ofthe-art catalysts.

\begin{tabular}{|c|c|c|c|c|c|}
\hline Catalyst & $\begin{array}{l}\mathrm{Pd} \\
{[\mathrm{wt} \%]}\end{array}$ & Ligand & $\begin{array}{l}\mathrm{S}_{\mathrm{H}_{2} \mathrm{O}_{2}} \\
{[\%]}\end{array}$ & $\begin{array}{l}r_{\mathrm{H}_{2} \mathrm{O}_{2} \text { formation }} \\
{\left[\mathrm{mol}_{\mathrm{H}_{2} \mathrm{O}_{2}} \mathrm{~h}^{-1} \mathrm{~g}_{\mathrm{Pd}}{ }^{-1}\right]}\end{array}$ & Ref. \\
\hline $\mathrm{Pd}-\mathrm{HHDMA} / \mathrm{C}$ & 0.6 & HHDMA & 80 & 8.4 & see $^{[b]}$ \\
\hline $\mathrm{Pd} / \mathrm{C}$ fibers & 1.0 & PVA & n.a. & 0.6 & [13] \\
\hline Pd/N-doped C & 0.9 & PVA & 45 & $14.2^{[a]}$ & [11 la] \\
\hline $\mathrm{Pd} / \mathrm{C}$ & 5.0 & none & n.a. & 2.7 & [6] \\
\hline $\mathrm{AuPd} / \mathrm{C}$ & 2.5 & none & 80 & 4.4 & {$[8 \mathrm{~b}]$} \\
\hline $\mathrm{SnPd} / \mathrm{TiO}_{2}$ & 3.0 & none & 96 & 2.0 & {$[8 c]$} \\
\hline
\end{tabular}

[a] $\mathrm{H}_{2} \mathrm{SO}_{4}$ was added to the reaction medium as promoter. [b] This work.

ity was comparable to that attained for the bimetallic AuPd system but lower than that recently reported for SnPd alloys supported on $\mathrm{TiO}_{2}$. Furthermore, the $\mathrm{H}_{2} \mathrm{O}_{2}$ hydrogenation activity was hindered upon increased amount of HHDMA and was negligible for the best-performing Pd-HHDMA $5 / \mathrm{C}$ catalyst. Additional $\mathrm{H}_{2} \mathrm{O}_{2}$ decomposition experiments showed that the rate of this reaction did not depend on the ligand content neither on the carbon support, despite a different $\mathrm{C}$ support was presumably used for the commercial preparation of $\mathrm{Pd}-\mathrm{HHDMA}_{5} / \mathrm{C}$. Accordingly, similar results were attained upon evaluation of the sole activated carbon (see Table S1 in the Supporting Information). The key influence of the support on this transformation was confirmed
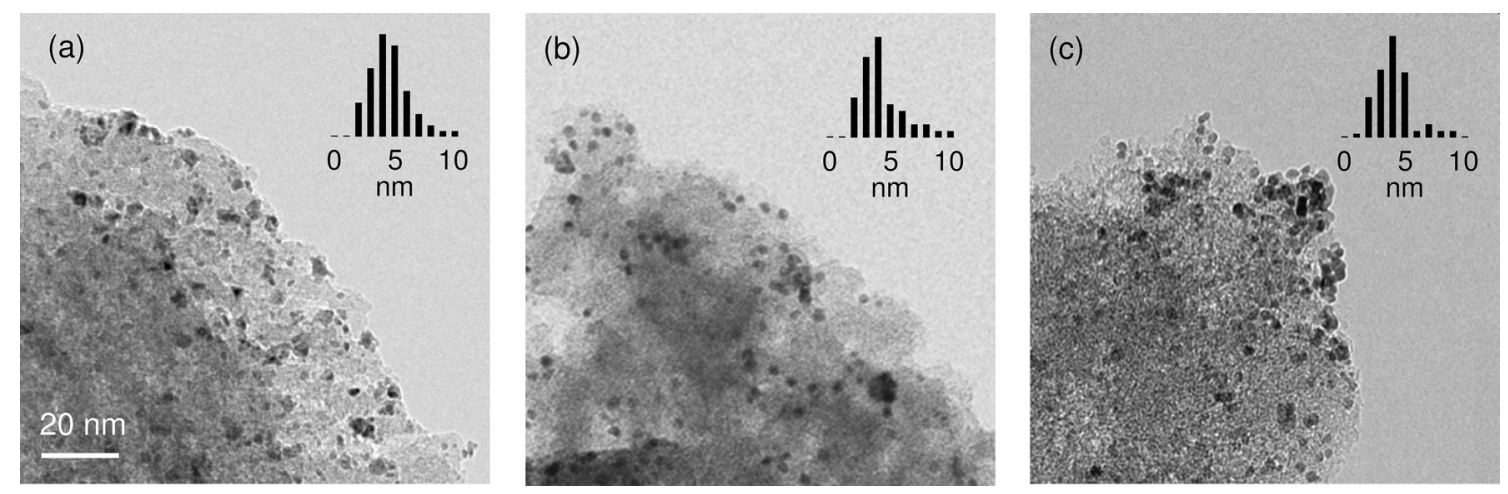

Figure 1. TEM of a) Pd-HHDMA $/$ C, b) fresh and c) used Pd-HHDMA $/$ C. The inset shows the particle size distributions and the scale bar applies to all the micrographs. 

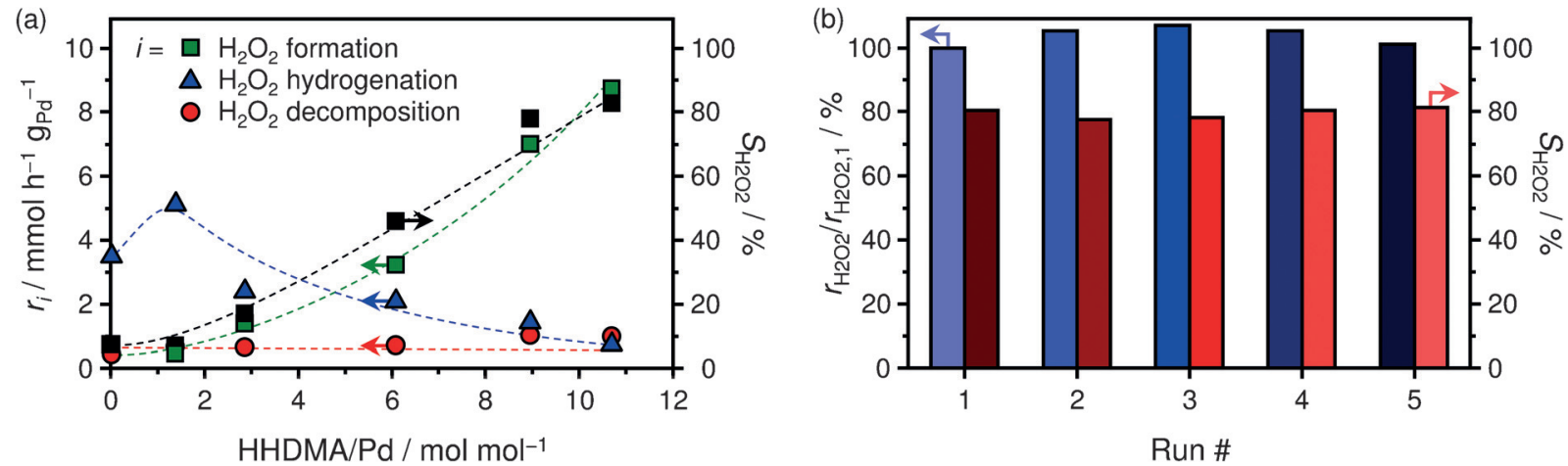

Figure 2. a) Effect of the $\mathrm{HHDMA} / \mathrm{Pd}$ molar ratio on the rates of $\mathrm{H}_{2} \mathrm{O}_{2}$ formation, decomposition, and hydrogenation and on the $\mathrm{H}_{2} \mathrm{O}_{2}$ selectivity. b) Fraction of the initial activity and $\mathrm{H}_{2} \mathrm{O}_{2}$ selectivity over $\mathrm{Pd}-\mathrm{HHDMA} / \mathrm{C}$ upon five consecutive runs. Conditions: $T=273 \mathrm{~K}, P=40$ bar, 3.75 vol $\%$ $\mathrm{H}_{2} ; 7.50$ vol $\% \mathrm{O}_{2} ; 88.75 \mathrm{vol} \% \mathrm{~N}_{2}, m_{\text {cat }}=10 \mathrm{mg}$ in $5 \mathrm{~cm}^{3}$ of $67 \mathrm{vol} \%$ methanol in water.

by the high decomposition rates observed over the bare TiS, which limited the productivity of $\mathrm{Pd}-\mathrm{HHDMA}_{5} / \mathrm{TiS}$ to $0.3 \mathrm{~mol}_{\mathrm{H}_{2} \mathrm{O}_{2}} \mathrm{~h}^{-1} \mathrm{~g}_{\mathrm{Pd}}{ }^{-1}$. Finally, the stability of the Pd$\mathrm{HHDMA}_{5} / \mathrm{C}$ catalyst was evaluated by monitoring the performance over five consecutive runs (Figure $2 \mathrm{~b}$ ), revealing that both the productivity and selectivity to $\mathrm{H}_{2} \mathrm{O}_{2}$ were maintained. Additional characterization of the used catalyst showed that, in contrasts to previous reports, ${ }^{[11 b]}$ the morphology of the Pd NPs was fully preserved (Figure 1c) and no leaching of Pd or ligand was observed upon ICP-OES analysis of the reaction mixtures.

DFT calculations performed over $\mathrm{Pd}(111)$ and $\mathrm{Pd}(111)$ HHDMA surfaces enabled to ascertain the key role of the ligand at the molecular scale. The complex structure of the hybrid surface has been disclosed previously, and was shown to comprise $\mathrm{H}_{2} \mathrm{PO}_{4}^{-}$groups strongly adsorbed on the metal surface, whose charge is compensated by the ammonium headgroups of the organic surfactant. ${ }^{[10 b]}$ The direct synthesis of $\mathrm{H}_{2} \mathrm{O}_{2}$ proceeds via $\mathrm{O}_{2}$ adsorption followed by two subsequent hydrogenation steps leading to an hydroperoxy $(\mathrm{OOH})$ and to $\mathrm{H}_{2} \mathrm{O}_{2}$. Overall, the activation energy for this path is lower on the naked $\left(0.74 \mathrm{eV}, 1 \mathrm{eV}=96 \mathrm{~kJ} \mathrm{~mol}^{-1}\right)$ than on the hybrid Pd surface (1.18 eV, Table S2). Nevertheless, the different selectivity observed experimentally can be explained considering the activation barriers for the selective and unselective transformations of the $\mathrm{OOH}$ intermediate (Figure 3 and Table S2). The over-hydrogenation and decomposition pathways are favored over $\operatorname{Pd}(111)$ compared to the formation of $\mathrm{H}_{2} \mathrm{O}_{2}$ (Figure $\mathrm{S} 1$ ). In contrast, on the $\mathrm{Pd}(111)$ HHDMA surface, not only the hydrogenation of the adsorbed $\mathrm{OOH}$ intermediate to $\mathrm{H}_{2} \mathrm{O}_{2}$ is preferred versus the overhydrogenation to water, but also the desorption of the product is energetically advantageous over its further hydrogenation and/or decomposition. Notably, the presence of the ligand increases the activation energy of the two side reactions. Furthermore, water formation attributed to $\mathrm{O}_{2}$ dissociation is only feasible on the naked Pd surface, while it is thermodynamically impeded on the Pd(111)-HHDMA surface (Table S3). Other hydrogenation pathways, involving the protonation of adsorbed species due to interfacial acidity ${ }^{[14]}$ are likely not taking place if the low energy barriers for $\mathrm{H}_{2}$ dissociation and $\mathrm{OOH}$ formation are considered.

The differences in the energy profiles between the naked and the hybrid Pd NPs arises from the adsorption configuration of $\mathrm{O}_{2}$ and the hydroperoxy radical. These intermediates flatten on the $\operatorname{Pd}(111)$ surface (Figures 3 and S2), thus favoring the cleavage of the $\mathrm{O}-\mathrm{O}$ bond. In contrast, on Pd(111)-HHDMA, the electrostatic interaction of the adsorbed intermediates with the $\mathrm{H}_{2} \mathrm{PO}_{4}^{-}$group and the quaternary ammonium headgroups of the HHDMA molecule

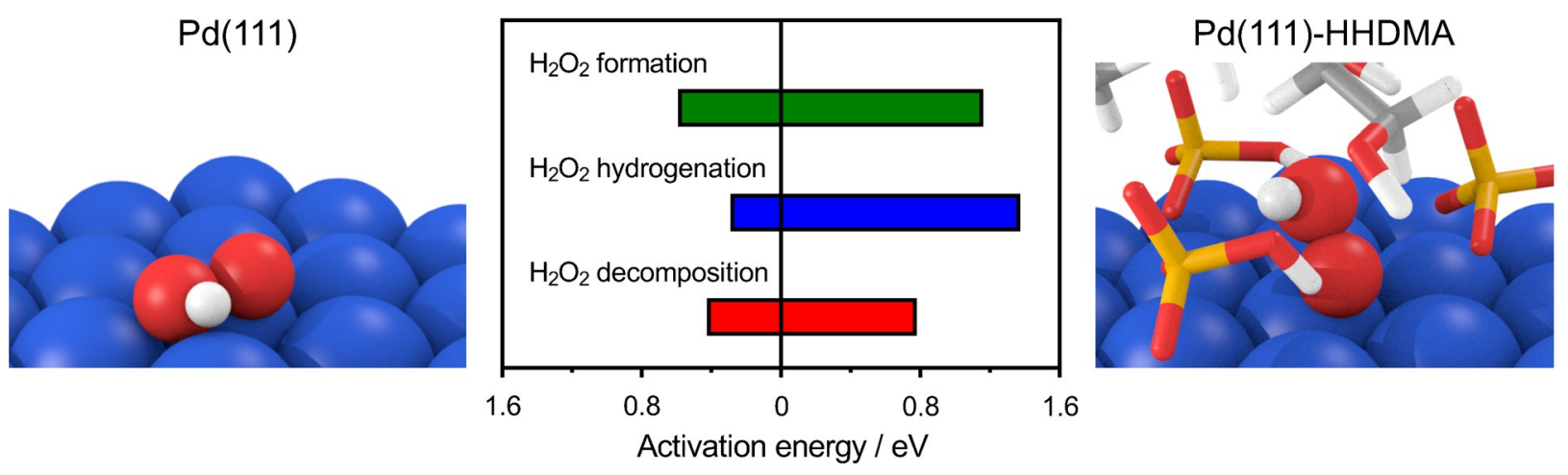

Figure 3. Central panel: activation energies for the direct synthesis of $\mathrm{H}_{2} \mathrm{O}_{2}$ and the side reactions leading to water formation by $\mathrm{H}_{2} \mathrm{O}_{2}$ hydrogenation and decomposition. The drawings represent the adsorption configuration of the hydroperoxy $(\mathrm{OOH})$ radical on $\mathrm{Pd}(111)$ and $\mathrm{Pd}(111)$-HHDMA surfaces. Color code: $\mathrm{H}$ in white, $\mathrm{C}$ in grey, $\mathrm{O}$ in red, $\mathrm{P}$ in yellow, and $\mathrm{Pd}$ in blue. 
enables the peculiar vertical configuration of the intermediate, impeding the cleavage of the $\mathrm{O}^{-} \mathrm{O}$ bond and its overhydrogenation. This is reflected by the decrease of the average atomic O-N distance from 6.64 to $5.95 \AA$ between the horizontal and the vertical adsorption (Figure S3). Such a ligand-imposed adsorption geometry resembles that observed at the active site of metalloenzymes, where the allowed reaction paths are determined by the directionality of the interaction between the substrate, the metal center, and the amino acid residues in the surroundings. Whether this behavior is unique to the HHDMA ligand clearly merits further exploration, especially as the interest in the role of electric fields in boosting selectivity is growing. ${ }^{[15]}$ Finally, it should be noted that, apart from the molecular reorientation on ligand-decorated structures, previously proposed as selectivity descriptors, ${ }^{[10 \mathrm{e}]}$ steric hindrance caused by the presence of the ligand can also contribute to the observed selectivity patterns as observed on earlier studies with bulkier molecules. ${ }^{[10 b]}$ However, the small size of the molecules involved in this case results in a minor impact of the ensemble confinement on the selective performance.

In conclusion, we have shown the outstanding activity, selectivity, and stability of carbon-supported HHDMAcapped $\mathrm{Pd}$ NPs in the direct synthesis of $\mathrm{H}_{2} \mathrm{O}_{2}$. Their performance was correlated with the amount of HHDMA ligand on the surface of the metal. DFT attributed this behavior to the adsorption mode of the reaction intermediates, deriving from their electrostatic interactions with the surfactant. The attained results not only demonstrate the applicability of hybrid materials for the direct synthesis of $\mathrm{H}_{2} \mathrm{O}_{2}$ but also highlight the importance of understanding the molecular role of the organic ligand for the design of novel nanocatalysts.

\section{Experimental Section}

Pd-HHDMA $_{n} / \mathrm{C}(n=1-4)$ catalysts were prepared by immobilizing onto activated carbon (NORIT) of colloids obtained using $\mathrm{Na}_{2} \mathrm{PdCl}_{4}$ (Sigma-Aldrich) as Pd precursor and varying amounts of HHDMA (Sigma-Aldrich) as stabilizing and reducing agent follow-

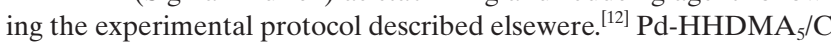
(NanoSelect LF $100^{\mathrm{TM}}$ ) and Pd-HHDMA ${ }_{5} /$ TiS (NanoSelect LF $200^{\mathrm{TM}}$ ), prepared industrially over unspecified carbon and titanium silicate supports following a similar procedure, were used as received. $\mathrm{Pd} / \mathrm{C}$ was prepared by dry impregnation of activated carbon using $\mathrm{Na}_{2} \mathrm{PdCl}_{4}$ as the metal precursor. The compositional and structural properties were studied by ICP-OES, elemental analysis, $\mathrm{CO}$ pulse chemisorption, and TEM measurements. Direct synthesis of $\mathrm{H}_{2} \mathrm{O}_{2}$ was conducted in a batch reactor at $273 \mathrm{~K}$ and a total pressure of $40 \mathrm{bar}\left(3.75 \mathrm{vol} \% \mathrm{H}_{2} ; 7.50 \mathrm{vol} \% \mathrm{O}_{2} ; 88.75 \mathrm{vol} \% \mathrm{~N}_{2}\right)$ using a $67 \mathrm{vol} \%$ methanol/water mixture as solvent and $10 \mathrm{mg}$ of catalyst. $\mathrm{H}_{2} \mathrm{O}_{2}$ (60 $\mathrm{mm}$ in $67 \mathrm{vol} \%$ methanol/water) hydrogenation and decomposition experiments were performed at 40 bar under $3.75 \mathrm{vol} \% \mathrm{H}_{2} / \mathrm{N}_{2}$ or $\mathrm{N}_{2}$ atmosphere, respectively. The reaction mixture was stirred for 30 minutes and the $\mathrm{H}_{2} \mathrm{O}_{2}$ formed was quantified by titration with $\mathrm{KMnO}_{4}$. The stability of $\mathrm{Pd}-\mathrm{HHDMA} / \mathrm{C}$ was assessed upon 5 consecutive catalytic runs. DFT calculations were conducted with the Vienna ab initio simulation package (VASP) ${ }^{[16]}$ using the RPBE functional and a kinetic cut-off energy of $450 \mathrm{eV}$. The $\operatorname{Pd}(111)$ slabs were constructed with five atomic layers which were periodically repeated and separated by a vacuum gap of $15 \AA$. The surface contained four adsorbed HHDMA molecules, whose alkyl chain has been shortened to lighten the calculations. The optimization thresholds were $10^{-5} \mathrm{eV}$ and $0.001 \mathrm{eV} \AA^{-1}$ for electronic and ionic relaxations, respectively. Further details on catalyst preparation, characterization, testing, and DFT simulations are given in the Supporting Information.

\section{Acknowledgements}

This work was funded by the Swiss National Science Foundation (grant number 200020-159760), the MINECO (grant number CTQ2015-68770-R) and Marie CurieCOFUND (grant number 291787-ICIQ-IPMP, M.S.). The Scientific Center for Optical and Electron Microscopy at ETH Zurich, ScopeM, is acknowledged for the use of its facilities. Dr. S. Mitchell is thanked for the TEM analyses.

\section{Conflict of interest}

The authors declare no conflict of interest.

Keywords: colloidal synthesis - density functional calculations . hybrid catalysts $\cdot$ palladium nanoparticles $\cdot$ peroxides

[1] Y. Yi, L. Wang, G. Li, H. Guo, Catal. Sci. Technol. 2016, 6, $1593-$ 1610.

[2] "Hydrogen Peroxide Market-Global Industry Analysis, Size, Share, Growth, Trends and Forecast, 2015-2023", can be found under https://globenewswire.com/.

[3] J. García-Serna, T. Moreno, P. Biasi, M. J. Cocero, J.-P. Mikkola, T. O. Salmi, Green Chem. 2014, 16, 2320-2343.

[4] J. M. Campos-Martin, G. Blanco-Brieva, J. L. G. Fierro, Angew. Chem. Int. Ed. 2006, 45, 6962-6984; Angew. Chem. 2006, 118, $7116-7139$.

[5] a) Q. Chen, E. J. Beckman, Green Chem. 2008, 10, 934-938; b) S. Shibata, T. Suenobu, S. Fukuzumi, Angew. Chem. Int. Ed. 2013, 52, 12327-12331; Angew. Chem. 2013, 125, 12553-12557; c) S. Fukuzumi, Biochim. Biophys. Acta Bioenerg. 2016, 1857, 604-611.

[6] E. N. Ntainjua, J. K. Edwards, A. F. Carley, J. A. López-Sánchez, J. A. Moulijn, A. A. Herzing, C. J. Kiely, G. J. Hutchings, Green Chem. 2008, 10, 1162-1169.

[7] A. Plauck, E. E. Stangland, J. A. Dumesic, M. Mavrikakis, Proc. Natl. Acad. Sci. USA 2016, 113, E1973-E1982.

[8] a) J. K. Edwards, J. Pritchard, L. Lu, M. Piccinini, G. Shaw, A. F. Carley, D. J. Morgan, C. J. Kiely, G. J. Hutchings, Angew. Chem. Int. Ed. 2014, 53, 2381-2384; Angew. Chem. 2014, 126, $2413-$ 2416; b) J. K. Edwards, B. Solsona, E. Ntainjua, A. F. Carley, A. A. Herzing, C. J. Kiely, G. J. Hutchings, Science 2009, 323, 1037-1041; c) S. J. Freakley, Q. He, J. H. Harrhy, L. Lu, D. A. Crole, D. J. Morgan, E. N. Ntainjua, J. K. Edwards, A. F. Carley, A. Y. Borisevich, C. J. Kiely, G. J. Hutchings, Science 2016, 351, 965-968; d) M. García-Mota, N. López, Phys. Chem. Chem. Phys. 2011, 13, 5790-5797; e) J. Li, T. Ishihara, K. Yoshizawa, J. Phys. Chem. C 2011, 115, 25359-25367; f) J. Li, K. Yoshizawa, Catal. Today 2015, 248, 142-148.

[9] C.-J. Jia, F. Schüth, Phys. Chem. Chem. Phys. 2011, 13, $2457-$ 2487.

[10] a) T. Bürgi, A. Baiker, Acc. Chem. Res. 2004, 37, 909-917; b) G. Vilé, N. Almora-Barrios, S. Mitchell, N. López, J. Pérez-Ramírez, 
Chem. Eur. J. 2014, 20, 5926-5937; c) T. Taguchi, K. Isozaki, K. Miki, Adv. Mater. 2012, 24, 6462-6467; d) Z. Niu, Y. Li, Chem. Mater. 2014, 26, 72 -83; e) S. T. Marshall, M. O'Brien, B. Oetter, A. Corpuz, R. M. Richards, D. K. Schwartz, J. W. Medlin, Nat. Mater. 2010, 9, 853-858; f) G. Chen, C. Xu, X. Huang, J. Ye, L. Gu, G. Li, Z. Tang, B. Wu, H. Yang, Z. Zhao, Z. Zhou, G. Fu, N. Zheng, Nat. Mater. 2016, 15, 564-569.

[11] a) S. Abate, R. Arrigo, M. E. Schuster, S. Perathoner, G. Centi, A. Villa, D. Sub, R. Schlögl, Catal. Today 2010, 157, 280-285; b) S. Abate, M. Freni, R. Arrigo, M. E. Schuster, S. Perathoner, G. Centi, Chem CatChem 2013, 5, 1899-1905.

[12] a) P. T. Witte, P. H. Berben, S. Boland, E. H. Boymans, D. Vogt, J. W. Geus, J. G. Donkervoort, Top. Catal. 2012, 55, 505-511; b) P. T. Witte, WO2009096783 A1, 2009.
[13] A. Villa, S. J. Freakley, M. Schiavoni, J. K. Edwards, C. Hammond, G. M. Veith, W. Wang, D. Wang, L. Prati, N. Dimitratos, G. J. Hutchings, Catal. Sci. Technol. 2016, 6, 694697.

[14] D. Albani, Q. Li, G. Vilé, S. Mitchell, N. Almora-Barrios, P. T. Witte, N. López, J. Pérez-Ramírez, Green Chem. 2016, DOI: 10.1039/C6GC02586B.

[15] S. Shaik, D. Mandal, R. Ramanan, Nat. Chem. 2016, 8, 1091 1098.

[16] G. Kresse, J. Furthmüller, Phys. Rev. B 1996, 54, 11169-11186. 